\title{
Clinicopathologic Factors Affecting Recurrence after Curative Surgery for Stage I Colorectal Cancer
}

\author{
Min Ae Keum, Seok-Byung Lim, Sun A Kim, Yong Sik Yoon, Chan Wook Kim, Chang Sik Yu, \\ Jin Cheon Kim \\ Departments of Surgery and ${ }^{1}$ Pathology, Asan Medical Center, University of Ulsan College of Medicine, Seoul, Korea
}

Purpose: The objective of the current study was to identify the clinicopathological risk factors affecting recurrence after a curative resection for stage I colorectal cancer.

Methods: We retrospectively studied 434 patients who underwent a curative resection for stage I colorectal cancer between January 1999 and December 2004. Postoperative oral chemotherapy was performed in 189 patients (45.3\%). The following prognostic factors were correlated with recurrence: age, gender, preoperative carcinoembryonic antigen level, location of tumor, T stage, size of tumor, histologic differentiation, growth pattern, and lymphovascular invasion. The median follow-up duration was 65 months.

Results: The overall recurrence rate was 4.6\% (20/434). The median time to recurrence was 33 months. Two-thirds of the recurrence occurred more than two years after surgery. Risk factors associated with recurrence were rectal cancer $(\mathrm{P}=$ 0.009), T2 stage $(\mathrm{P}=0.010)$, and infiltrative growth pattern $(\mathrm{P}=0.020)$. A Cox proportional hazards regression analysis demonstrated that the infiltrative growth pattern was an independent predictor for recurrence. Tumor cell budding was observed in all pathologic reviews with recurrence.

Conclusion: Long-term follow-up is necessary for stage I colorectal patients with high risk factors like rectal cancer, T2 stage, and infiltrative growth pattern.

Keywords: Colorectal neoplasms; Recurrence; Risk factors

\section{INTRODUCTION}

Colorectal cancer is the third most prevalent cancer in South Korea, following gastric cancer and thyroid cancer. It accounts for $12.7 \%$ of all cancers, and its prevalence is increasing [1]. Because the number of early diagnoses of the stage I colorectal cancer is tending to increase as the number of people being screened with occult blood tests and colonoscopy through the national campaign for cancer screening has increased [2], an excellent prognosis of greater than

Received: August 31, 2011 Revised: October 19, 2011

Accepted: November 16, 2011

Correspondence to: Jin Cheon Kim, M.D.

Department of Surgery, Asan Medical Center, University of Ulsan College of Medicine, 88 Olympic-ro 43-gil, Songpa-gu, Seoul 138-736, Korea

Tel: +82-2-3010-3489, Fax: +82-2-3010-6701

E-mail: jckim@amc.seoul.kr

(C) 2012 The Korean Society of Coloproctology

This is an open-access article distributed under the terms of the Creative Commons Attribution NonCommercial License (http://creativecommons.org/licenses/by-nc/3.0) which permits unrestricted noncommercial use, distribution, and reproduction in any medium, provided the original work is properly cited.
90\% 5-year survival post radical resection is being achieved [3]. Although 10 to $13 \%$ of stage I colorectal cancer patients who undergo a radical resection experience recurrence, adjuvant chemotherapy is generally not recommended for them because it does not improve their survival rate $[4,5]$. The purpose of this study is to select clinicopathologic factors related to the recurrence among stage I colorectal cancer patients who undergo a radical resection.

\section{METHODS}

Among the 4.489 patients who had radical resections due to colorectal carcinomas in this Department of Colorectal Surgery between January 1999 and December 2004, 515 patients (11.4\%) were diagnosed with first-stage colorectal cancer on histopathologic examination. A radical resection is defined as a surgical resection that ligates the origin of feeding vessels and takes all lymph nodes between the pericolic lymph nodes and the principle lymph nodes. Among these 515 patients, familial adenomatous polyposis (21 patients), hereditary non-polyposis colorectal cancer (14 patients) and patients who had preoperative chemoradiation therapy (46 
Table 1. Clinicopathologic characteristics for patients with stage I colorectal cancer $(\mathrm{n}=434)$

\begin{tabular}{|c|c|}
\hline Characteristic & Value \\
\hline Age (yr) & $60.5(11.2)$ \\
\hline \multicolumn{2}{|l|}{ Sex } \\
\hline Male & $250(57.6)$ \\
\hline Female & $184(42.4)$ \\
\hline CEA (ng/mL) & $4.2(5.1)$ \\
\hline \multicolumn{2}{|l|}{ Location of tumor } \\
\hline Colon & $145(33.4)$ \\
\hline Rectum & $289(66.6)$ \\
\hline \multicolumn{2}{|l|}{ Operation } \\
\hline ICR & $1(0.2)$ \\
\hline $\mathrm{RHC}$ & $30(6.9)$ \\
\hline LHC & $6(1.4)$ \\
\hline AR & $99(22.8)$ \\
\hline LAR & $147(33.9)$ \\
\hline ULAR & $72(16.6)$ \\
\hline APR & $77(17.7)$ \\
\hline $\mathrm{TC}$ & $2(0.5)$ \\
\hline \multicolumn{2}{|l|}{ T stage } \\
\hline $\mathrm{T} 1$ & $132(30.4)$ \\
\hline $\mathrm{T} 2$ & $302(69.6)$ \\
\hline \multicolumn{2}{|l|}{ Size $(\mathrm{cm})$} \\
\hline$<4$ & $252(58.1)$ \\
\hline$<4$ & $182(41.9)$ \\
\hline \multicolumn{2}{|l|}{ Growth type } \\
\hline Expanding (B-1/II) & $388(89.4)$ \\
\hline Infiltrative (B-III/IV) & $46(10.6)$ \\
\hline \multicolumn{2}{|l|}{ Differentiation } \\
\hline WD/MD & $421(97.0)$ \\
\hline $\mathrm{PD} / \mathrm{SRC}$ & $13(3.0)$ \\
\hline \multicolumn{2}{|l|}{ Lymphovascular invasion } \\
\hline No & $390(89.8)$ \\
\hline Yes & $44(10.2)$ \\
\hline No. of harvested lymph nodes & $13.1(8.1)$ \\
\hline \multicolumn{2}{|c|}{ Postoperative immunochemotherapy } \\
\hline No & $245(56.5)$ \\
\hline Yes & 189 (43.5) \\
\hline
\end{tabular}

Values are presented as mean (SD) or number (\%).

$\mathrm{SD}$, standard deviation; CEA, carcinoembryonic antigen; ICR, ileocecal resection; $\mathrm{RHC}$, right hemicolectomy; LHC, left hemicolectomy; AR; anterior resection; LAR, Iow anterior resection; ULAR, ultralow anterior resection; APR, abdominoperineal resection; TC, total colectomy; B-1/II, Bormann type-fungating/ulcerofungating; BIII/IV, Bormann type-ulceroinfiltrative/infiltrative; WD, well-differentiated; MD, moderatelydifferentiated; PD, poorly differentiated; SRC, signet ring cell. patients) were excluded, and finally 434 patients were chosen as subjects for this study. Retrospective analyses of clinicopathologic factors and of follow-up test results were conducted with prospectively collected data. Among the 434 subjects, 189 had postoperative oral immunochemotherapy. The surgeons decided on this for patients carrying a high risk of recurrence as they presented with evidence of lymphovascular invasion or T2 stage, poorly differentiated cancer, and signet ring cell carcinomas during the surgery and on the pathologic diagnosis. Single oral chemotherapy (tegafur/uracil or doxifluridine) or one combined with an immune modulator (polysaccharide-k) therapy was administered for at least 3 months up to 12 months; 113 patients among 189 patients had the combined therapy.

All the subjects were categorized into the recurrence group and the non-recurrence group during the follow-up period, and their clinicopathologic factors (age, sex, preoperative carcinoembryonic antigen value, the location of tumor T stage [T1 or T2], the size of tumors, the gross finding of the tumor [fungating type or infiltrative type], histologic grade, lymphovascular invasion, the number of obtained lymph nodes, postoperative oral immunochemotherapy) were compared and analyzed. The diagnosis of recurrence was completed by radiological or histological investigation, and the time to recurrence was counted from the operation day. Local recurrence was defined as occurring when the cancer was recurrent in the anastomosis site or in the structure of the pelvic cavity (vagina, bladder, and lymph nodes located in the pelvic cavity), and distant recurrence was defined as occurring when the cancer was recurrent in the systemic lymph nodes, liver, lung, peritoneum, bones and brain [6]. The mean period of follow-up

Table 2. Clinicopathologic characteristics for patients with recurrence $(\mathrm{n}=20)$

\begin{tabular}{lc}
\hline Characteristic & Value \\
\hline Time to recurrence (mo), median (range) & 33 (3-71) \\
Site of recurrence (no. of cases) & \\
Local & 3 \\
$\quad$ Presacral mass & 2 \\
$\quad$ Anastomosis & 2 \\
$\quad$ Pelvic wall & \\
Distant & 4 \\
$\quad$ Liver & 4 \\
$\quad$ Lung & 4 \\
Others & 1 \\
Combined & \\
Treatment for recurrent disease (no. of cases) & 5 \\
Operation \& chemotherapy & 8 \\
\hline Chemotherapy or radiation therapy & 7 \\
\hline Conservative management &
\end{tabular}


Volume 28, Number 1, 2012

of all the patients was 65 months (2 to 127 months). An independent-sample t-test for continuous variables and a chi-square test for nominal variables were conducted. A multivariate analysis was conducted for clinicopathologic factors that were judged to be statistically significant through a Kaplan-Meier survival analysis, and the Cox regression model was used for the analysis. Results were judged to be statistically significant when P-value was less than 0.05 bilaterally.

\section{RESULTS}

Table 1 summarized the clinicopathologic characteristics of the 434 patients who were diagnosed with stage I colorectal cancer after a radical resection due to a sporadic colorectal carcinoma. Recurrence was identified in $20(4.6 \%)$ patients during the followup period, and they were classified as the recurrence group. The median value of the time to recurrence was 33 months (range, 3 to 71 months). The invasion depth of the recurrent T1 stage patients was sm3. Among the 20 patients experiencing recurrence, 5 had a reoperation and chemotherapy, 8 had chemotherapy and radiotherapy, and 7 had only symptom-control treatments. Of the 20,14 expired during the follow-up period. The mean survival period of the remaining 6 patients was 39 months (range, 14 to 68 months) after the above treatments for recurrence, and only 2 patients among the 6 survived longer than 5 years. Table 2 presents the clinicopathologic findings, the location of recurrence, the treat-

Table 3. Univariate and multivariate analysis of prognostic factors in stage I colorectal cancer

\begin{tabular}{|c|c|c|c|c|c|}
\hline Variable & $\begin{array}{l}\text { Without recurrence } \\
\qquad(\mathrm{n}=414)\end{array}$ & $\begin{array}{l}\text { With recurrence } \\
\qquad(\mathrm{n}=20)\end{array}$ & $\begin{array}{l}\text { Univariate } \\
\text { P-value }\end{array}$ & $\begin{array}{l}\text { Multivariate } \\
\text { P-value }\end{array}$ & $\mathrm{HR}(95 \% \mathrm{Cl})$ \\
\hline Age (yr) & $60.3(11.3)$ & $64.7(8.9)$ & 0.085 & & \\
\hline Sex & & & 0.551 & & \\
\hline Male & $240(96)$ & $10(4)$ & & & \\
\hline Female & $174(94.6)$ & $10(5.4)$ & & & \\
\hline CEA (ng/mL) & $4.1(5.1)$ & $5.1(5.4)$ & 0.390 & & \\
\hline Location of tumor & & & 0.009 & 0.061 & \\
\hline Colon & $143(99.3)$ & $1(1.4)$ & & & \\
\hline Rectum & $271(93.4)$ & $19(6.6)$ & & & \\
\hline T stage & & & 0.010 & 0.064 & \\
\hline $\mathrm{T} 1$ & 131 (99.2) & $1(0.8)$ & & & \\
\hline $\mathrm{T} 2$ & $283(93.7)$ & $19(6.3)$ & & & \\
\hline Size (cm) & & & 0.379 & & \\
\hline$<4$ & $242(96.0)$ & $10(4.0)$ & & & \\
\hline$\geq 4$ & $173(94.5)$ & $19(5.5)$ & & & \\
\hline Growth type & & & 0.017 & 0.020 & $3.36(1.21-9.34)$ \\
\hline Expanding (B-1/II) & $373(96.1)$ & $15(3.9)$ & & & \\
\hline Infiltrative (B-III/IV) & $41(89.1)$ & $5(10.9)$ & & & \\
\hline Differentiation & & & 0.068 & & \\
\hline WD/MD & $403(95.7)$ & $18(4.3)$ & & & \\
\hline PD/SRC & $11(84.6)$ & $2(15.4)$ & & & \\
\hline Lymphovascular invasion & & & 0.520 & & \\
\hline No & 373 (95.6) & $17(4.4)$ & & & \\
\hline Yes & $41(93.2)$ & $3(6.8)$ & & & \\
\hline No. of harvested lymph nodes & $13.1(8.1)$ & $14.0(7.9)$ & 0.637 & & \\
\hline Postoperative immunochemotherapy & & & 0.181 & & \\
\hline No & 237 (96.7) & 8 (3.3) & & & \\
\hline Yes & $177(93.7)$ & $12(6.3)$ & & & \\
\hline
\end{tabular}

Values are presented as mean (SD) or number (\%).

HR, hazard ratio; Cl, confidence interval; SD, standard deviation; CEA, carcinoembryonic antigen; B-I/II, Bormann type-fungating/ulcerofungating; B-III/IV, Bormann typeulceroinfiltrative/infiltrative; WD, well-differentiated; MD, moderately differentiated; PD, poorly differentiated; SRC, signet ring cell.

Univariate analysis, Kaplan-Meier; multivariate analysis, Cox regression. 
Table 4. Univariate and multivariate analysis of postoperative oral immunochemotherapy

\begin{tabular}{|c|c|c|c|c|c|c|c|}
\hline \multirow[b]{2}{*}{ Variable } & \multicolumn{3}{|c|}{ PICTx (+) (n= 189, 45.3\%) } & \multicolumn{4}{|c|}{ PICTx (-) $(n=245,54.7 \%)$} \\
\hline & $\begin{array}{l}\text { Without } \\
\text { recurrence } \\
(n=177)\end{array}$ & $\begin{array}{c}\text { With } \\
\text { recurrence } \\
(n=12)\end{array}$ & $\begin{array}{l}\text { Univariate } \\
\text { P-value }\end{array}$ & $\begin{array}{l}\text { Without } \\
\text { recurrence } \\
(n=237)\end{array}$ & $\begin{array}{l}\text { With } \\
\text { recurrence } \\
(n=8)\end{array}$ & $\begin{array}{l}\text { Univariate } \\
\text { P-value }\end{array}$ & $\begin{array}{c}\text { Multivariate } \\
\text { P-value }\end{array}$ \\
\hline Age (yr) & & & 0.785 & & & 0.001 & 0.946 \\
\hline$<65$ & 143 & 9 & & 129 & 0 & & \\
\hline$\geq 65$ & 46 & 3 & & 116 & 8 & & \\
\hline Sex & & & 0.822 & & & 0.582 & \\
\hline Male & 97 & 6 & & 143 & 4 & & \\
\hline Female & 80 & 6 & & 94 & 4 & & \\
\hline CEA (ng/mL) & & & 0.527 & & & $<0.001$ & 0.066 \\
\hline$<6$ & 163 & 11 & & 219 & 4 & & \\
\hline$\geq 6$ & 26 & 1 & & 26 & 4 & & \\
\hline Location & & & 0.507 & & & 0.026 & 0.951 \\
\hline Colon & 47 & 2 & & 96 & 0 & & \\
\hline Rectum & 130 & 10 & & 141 & 8 & & \\
\hline T stage & & & 0.462 & & & 0.018 & 0.744 \\
\hline $\mathrm{T} 1$ & 8 & 0 & & 123 & 1 & & \\
\hline T2 & 169 & 12 & & 114 & 7 & & \\
\hline Size $(\mathrm{cm})$ & & & 0.837 & & & 0.206 & \\
\hline$<4$ & 83 & 6 & & 159 & 4 & & \\
\hline$\geq 4$ & 94 & 6 & & 78 & 4 & & \\
\hline Growth & & & 0.053 & & & 0.052 & \\
\hline$B-1 / / I$ & 157 & 9 & & 216 & 6 & & \\
\hline B-III/IV & 20 & 3 & & 21 & 2 & & \\
\hline Differentiation & & & 0.296 & & & 0.082 & \\
\hline WD/MD & 172 & 11 & & 231 & 7 & & \\
\hline PD/SRC & 5 & 1 & & 6 & 1 & & \\
\hline LVi & & & 0.788 & & & 0.540 & \\
\hline No & 153 & 10 & & 220 & 7 & & \\
\hline Yes & 24 & 2 & & 17 & 1 & & \\
\hline
\end{tabular}

PICTX, postoperative oral immunochemotherapy; CEA, carcinoembryonic antigen; B-I/II, Bormann type-fungating/ulcerofungating; B-III/IV, Bormann type-ulceroinfiltrative/ infiltrative; WD, well-differentiated; MD, moderately differentiated; PD, poorly differentiated; SRC, signet ring cell carcinoma; LVi, lymphovascular invasion.

Regimen of postoperative oral immunochemotherapy: single or combination therapy of oral chemotherapy agent (tegafur/uracil or doxifluridine) and immune modulator (polysaccharide-K) for 3 to 12 months.

Univariate analysis, Kaplan-Meier; multivariate analysis, Cox regression.

ments, and the progress of the disease for the recurrence group.

Table 3 presents a comparative analysis of the clinicopathologic findings for the recurrence group and for the non-recurrence group. The location of the tumor $(\mathrm{P}=0.009)$, $\mathrm{T}$ stage $(\mathrm{P}=0.010)$ and gross finding $(\mathrm{P}=0.017)$ were found to be significant in the univariate analysis of the clinicopathologic factors affecting recurrence. A multivariate analysis was conducted on the clinicopathologic factors found to be significant in the univariate analysis, and the gross finding of the tumor $(\mathrm{P}=0.020)$ was identified as an in- dependent factor affecting recurrence. Table 4 presents the postoperative oral immunochemotherapy and clinicopathologic findings for the recurrence group and the non-recurrence group. It shows that postoperative oral immunochemotherapy had no statistically significance relation to recurrence. The pathology slides of the patients experiencing recurrence were analyzed again by another pathologist for the presence of tumor cell budding, which was found in all the patients experiencing recurrence (Fig. 1). 
Table 5. Previous studies for stage I colorectal cancer

\begin{tabular}{lcccc}
\hline Author & Journal (yr) & No. of patients & Recurrence (\%) & Risk factors \\
\hline Willett et al. [8] & Cancer (1992) & 64 & 8 (12.5) & T2, LVi \\
Sticca et al. [9] & Cancer Invest (1996) & 71 & $7(10)$ & T2 \\
Blumberg et al. [7] & J Am Coll Surg (1998) & 211 & $22(12)$ & Male, BVi \\
Wichmann et al. [10] & World J Surg (2002) & $296(10)$ & T2, high CEA level \\
Present study & & 434 & $20(4.6)$ & Growth pattern \\
\hline
\end{tabular}

LVi, lymphovascular invasion; BVi, blood vessel invasion; CEA, carcinoembryonic antigen.

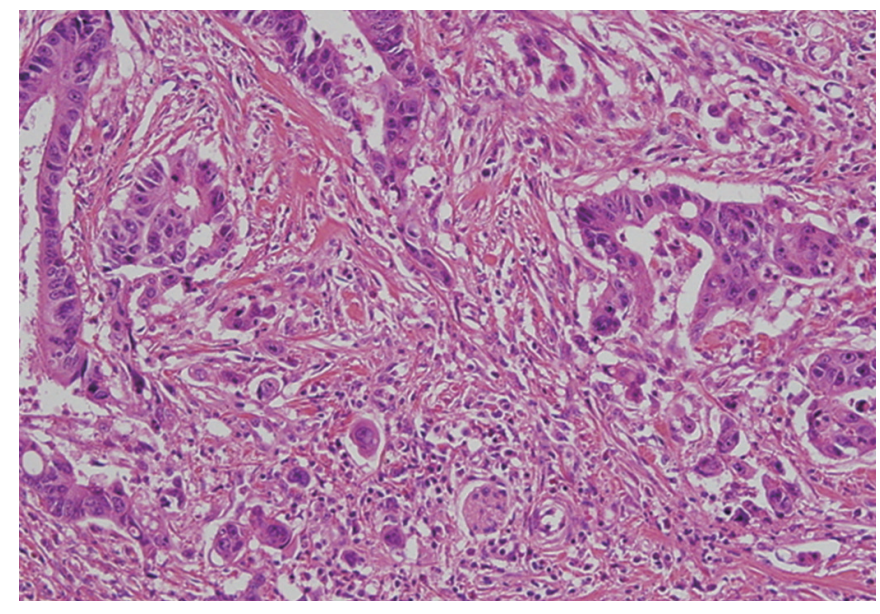

Fig. 1. Photomicrography of tumor cell budding. An isolated single cancer cell and a cluster composed of fewer than five cancer cells are identified at the invasive front of the tumor $(\mathrm{H} \& \mathrm{E}, \times 200)$.

\section{DISCUSSION}

The overall prognosis for stage I colorectal cancer shows an excellent outcome of greater than $90 \%$ for the 5-year survival rate [3], but 10 to $13 \%$ of the patients still experience recurrence [7-10]. T2 stage tumor [8-10], lymphovascular invasion [7, 8], lower rectal lesions [9], male sex [7], a poorly-differentiated carcinoma [7] and high preoperative carcinoembryonic antigen value [10] were identified as influential factors related to the recurrence of stage I colorectal cancer in previous studies. Table 5 summarizes the results of previous studies related to the recurrence of first-stage colorectal cancer and compares them with the results of this study. In this study, infiltrative type on the gross finding was identified as an independent factor affecting the recurrence in stage I colorectal cancer. An infiltrative type of colorectal cancer has been reported to have a significant effect on recurrence because it invades the pericolorectal fatty tissues and lymph nodes more rapidly than the fungating type [11-13]. Steinberg et al. [11] reported that among influential factors affecting the prognosis of colon cancer after surgical interventions, the relative risk was $0.52(\mathrm{P}=0.004)$ when a fungating type of colorectal cancer existed on the gross finding. Manfredi et al. [12] reported that the relative risk of an infiltrative type of colorectal cancer was 1.2 times greater $(\mathrm{P}=0.037)$ than that of a fungating type of colorectal cancer when it comes to distant recurrence.

The presence of tumor cell budding was found in the pathology slides of all 20 patients experiencing recurrence in this study. Tumor cell budding is known to be related to metastasis to lymph nodes $[14,15]$ and lymphovascular invasion [16] in cases of a submucosal invasive colorectal carcinoma. Hase et al. [17] analyzed the prognosis of colorectal cancer for 663 patients having had a radical resection after classifying the grade of tumor cell budding into two groups and concluded that tumor cell budding was a powerful prognostic factor because a significant difference in recurrence rates $(71.1 \%$ vs. $22.2 \%, \mathrm{P}<0.005)$ and in 10 -year survival rates $(50.6 \%$ vs. $13.8 \%, \mathrm{P}<0.001)$ existed. Ueno et al. [18] established their own criterion, named high-grade budding ( $>10$ foci within a microscopic field of $\mathrm{x} 250$ ), and reported that high-grade budding was related to aggressive characteristics such as histological grade, proper muscle invasion, lymph-node metastasis, growth patterns and vascular invasion. Classifying the grade of tumor cell budding of the patients experiencing recurrence in this study, highgrade budding (as it was defined by Ueno et al.) was observed in 8 cases (40\%). Although the presence of tumor cell budding or high-grade budding was not found to be an influential factor affecting the recurrence of the stage I colorectal cancer because the result of tumor cell budding of the non-recurrence group was not confirmed in this study, further studies regarding tumor cell budding are thought to be required because the finding of tumor cell budding is judged to be related to the growth patterns and the histological grade of the tumor.

When a univariate analysis for the characteristics of recurrence according to the location of the primary tumor, rectal cancer showed a higher recurrence rate than colon cancer $(6.6 \%$ vs. $1.4 \%, \mathrm{P}=$ 0.009). Although no significant difference between the recurrence rate at the upper rectum and at the lower rectum in rectal cancer was noted, 17 cases (90\%) among 19 cases of recurrent rectal cancer were located in the middle and in the lower rectum, indicating the characteristics of recurrence were different between the two locations. T stage tumors are known to be an independent factor related to the recurrence of colorectal cancer, and T2 stage identified in stage I colorectal cancer patients has been reported to be an independent factor related to recurrence $[10,13,19,20]$. In this 
study, T2 stage was not identified as a significant influential factor related to recurrence $(\mathrm{P}=0.064)$. The reason for this is thought to be the number of the patients, and a more significant result should be gained with bigger samples in further studies. Male sex and lymphovascular invasion were also identified as risk factors related to recurrence of stage I colorectal cancer in previous studies, although significant statistical results were not obtained in this study. Male sex has been understood as a poor prognostic factor for a long time, and in recent years, it has been recognized more as an independent poor prognostic factor in stage II and III rectal cancer [21]. Lymphovascular invasions have been reported as a poor prognostic factor in colorectal cancer patients $[22,23]$. The authors reported that the recurrence rate was significantly higher when lymphovascular invasion was identified in sporadic colorectal cancer. Also, especially in recent studies, recurrence in systemic lymph nodes was significant [24]. About $80 \%$ of the recurrences after a radical resection in colorectal cancer usually occurs within 2 years [25-27]. However, only 8 cases of recurrence (40\%) among the 20 cases in this study occurred within 2 years, 10 (50\%) occurred between 2 years and 5 years, and the remaining 2 occurred after 5 years. The median value of the time to recurrence was 33 months in this study, which was rather different from the results of existing studies (12 to 22 month) [25]. Aghili et al. [28], in a study addressing early and late recurrence of colorectal cancer, reported that $70 \%$ of the recurrences in colorectal cancer occurred at an early stage within 2 years and that the factors related to early recurrence were young age, invasion to proximal organs and Duke $\mathrm{C}$ stage. The relatively low early recurrence in this study was estimated to be related to the characteristics of the stage I colorectal cancer where invasion to the intestinal wall was limited to the proper muscle.

Hepatic metastasis was reported to be the most common metastasis occurring within two years from the radical resection in studies analyzing the characteristics of recurrence, but after two years, pulmonary metastasis was most commonly seen and was reported as the most common distant metastatic lesion [25]. In this study, one recurrence case from left colon cancer was a hepatic metastasis, and three out of the four cases of pulmonary metastasis from rectal cancer occurred within two years. Six out of the 7 cases of local recurrence from rectal cancer occurred after two years which was distinctive from the existing results showing similar local recurrence rate over the time $[25,28]$. Even though a statistically significant comparison was difficult as the size of the sample was small, this recurrence pattern of stage I colorectal cancer is thought to be related to the characteristics of stage I colorectal cancer where invasion is limited to the proper muscle.

Among the 434 patients, 189 underwent postoperative oral immunochemotherapy, but no statistical significance was attached to the way in which the treatment affected the recurrence. However, the conduct of the statistical analysis might have been limited because the surgeons decided on the method and the drug for the therapy by referencing the operation and the pathological finding when they chose the patients for the therapy.
In conclusion, although the recurrence rate of colorectal cancer is around $10 \%$, it is rare for patients to survive longer than 5 years. According to the results in this study, stage I colorectal cancer patients with infiltrative type cancer on the gross finding and with high-grade tumor cell budding were identified as a high risk group, and this should be borne in mind during the follow-up. Moreover, longer follow-up is advised for the high-risk group with rectal cancer, T2 stage and infiltrative type, because, contrary to the recurrence patterns for stage II and III colorectal cancer, more than $60 \%$ of the recurrences of stage I colorectal cancer occurred after 2 years.

\section{CONFLICT OF INTEREST}

No potential conflict of interest relevant to this article was reported.

\section{REFERENCES}

1. Cancer.go.kr [Internet]. Goyang: National Cancer Information Cencer, Korea Central Cancer Registry; 2008 [cited 2011 Aug 1]. Cancer incidence in Korea 1999-2002. Available from: http:// www.cancer.go.kr/cms/data/edudata/_icsFiles/afieldfile/2009/ 09/16/aa(aa0606).pdf.

2. Park DD, Shin R, Kim JS, Oh HK, Jeong SY, Park KJ, et al. Clinical features of colorectal cancer detected by the national cancer screening program. J Korean Soc Coloproctol 2010;26:420-3.

3. Edge SB; American Joint Committee on Cancer. AJCC cancer staging manual. 7th ed. New York: Springer; 2010.

4. Cohen AM, Kelsen D, Saltz L, Minsky BD, Nelson H, Farouk R, et al. Adjuvant therapy for colorectal cancer. Curr Probl Surg 1997; 34:601-76.

5. Moertel CG, Fleming TR, Macdonald JS, Haller DG, Laurie JA, Goodman PJ, et al. Levamisole and fluorouracil for adjuvant therapy of resected colon carcinoma. N Engl J Med 1990;322:352-8.

6. Stipa S, Nicolanti V, Botti C, Cosimelli M, Mannella E, Stipa F, et al. Local recurrence after curative resection for colorectal cancer: frequency, risk factors and treatment. J Surg Oncol Suppl 1991;2: 155-60.

7. Blumberg D, Paty PB, Picon AI, Guillem JG, Klimstra DS, Minsky $\mathrm{BD}$, et al. Stage I rectal cancer: identification of high-risk patients. J Am Coll Surg 1998;186:574-9.

8. Willett CG, Lewandrowski K, Donnelly S, Shellito PC, Convery K, Eliseo R, et al. Are there patients with stage I rectal carcinoma at risk for failure after abdominoperineal resection? Cancer 1992; 69:1651-5.

9. Sticca RP, Rodriguez-Bigas M, Penetrante RB, Petrelli NJ. Curative resection for stage I rectal cancer: natural history, prognostic factors, and recurrence patterns. Cancer Invest 1996;14:491-7.

10. Wichmann MW, Müller C, Hornung HM, Lau-Werner U, Schildberg FW; Colorectal Cancer Study Group. Results of long-term follow-up after curative resection of Dukes A colorectal cancer. World J Surg 2002;26:732-6. 
11. Steinberg SM, Barwick KW, Stablein DM. Importance of tumor pathology and morphology in patients with surgically resected colon cancer. Findings from the Gastrointestinal Tumor Study Group. Cancer 1986;58:1340-5.

12. Manfredi S, Bouvier AM, Lepage C, Hatem C, Dancourt V, Faivre $J$. Incidence and patterns of recurrence after resection for cure of colonic cancer in a well defined population. Br J Surg 2006;93: 1115-22.

13. Michelassi F, Vannucci L, Montag A, Goldberg R, Chappell R, Dytch $\mathrm{H}$, et al. Importance of tumor morphology for the long term prognosis of rectal adenocarcinoma. Am Surg 1988;54:376-9.

14. Choi PW, Yu CS, Jang SJ, Jung SH, Kim HC, Kim JC. Risk factors for lymph node metastasis in submucosal invasive colorectal cancer. World J Surg 2008;32:2089-94.

15. Hori H, Fujimori T, Fujii S, Ichikawa K, Ohkura Y, Tomita S, et al. Evaluation of tumor cell dissociation as a predictive marker of lymph node metastasis in submucosal invasive colorectal carcinoma. Dis Colon Rectum 2005;48:938-45.

16. Okuyama T, Oya M, Ishikawa $H$. Budding as a risk factor for lymph node metastasis in pT1 or pT2 well-differentiated colorectal adenocarcinoma. Dis Colon Rectum 2002;45:628-34.

17. Hase K, Shatney C, Johnson D, Trollope M, Vierra M. Prognostic value of tumor "budding" in patients with colorectal cancer. Dis Colon Rectum 1993;36:627-35.

18. Ueno H, Murphy J, Jass JR, Mochizuki H, Talbot IC. Tumour 'budding' as an index to estimate the potential of aggressiveness in rectal cancer. Histopathology 2002;40:127-32.

19. Müller JM, Tübergen D, Zieren U. After-care in colorectal cancerdata and patient oriented evaluation. Zentralbl Chir 1994;119: 6574.
20. Newland RC, Dent OF, Lyttle MN, Chapuis PH, Bokey EL. Pathologic determinants of survival associated with colorectal cancer with lymph node metastases. A multivariate analysis of 579 patients. Cancer 1994;73:2076-82.

21. Chapuis PH, Dent OF, Fisher R, Newland RC, Pheils MT, Smyth E, et al. A multivariate analysis of clinical and pathological variables in prognosis after resection of large bowel cancer. Br J Surg 1985; 72:698-702.

22. Minsky BD, Mies C, Rich TA, Recht A, Chaffey JT. Potentially curative surgery of colon cancer: the influence of blood vessel invasion. J Clin Oncol 1988;6:119-27.

23. Horn A, Dahl O, Morild I. The role of venous and neural invasion on survival in rectal adenocarcinoma. Dis Colon Rectum 1990;33: 598-601.

24. Lim SB, Yu CS, Jang SJ, Kim TW, Kim JH, Kim JC. Prognostic significance of lymphovascular invasion in sporadic colorectal cancer. Dis Colon Rectum 2010;53:377-84.

25. Park IJ, Kim HC, Yu CS, Kim JC. Pattern of recurrences and metastases after a curative resection for primary colorectal cancer. J Korean Soc Coloproctol 2008;24:207-13.

26. Griesenberg D, Nürnberg R, Bahlo M, Klapdor R. CEA, TPS, CA 19-9 and CA 72-4 and the fecal occult blood test in the preoperative diagnosis and follow-up after resective surgery of colorectal cancer. Anticancer Res 1999;19(4A):2443-50.

27. Steele G Jr. Follow-up plans after treatment of primary colon and rectum cancer. World J Surg 1991;15:583-8.

28. Aghili M, Izadi S, Madani H, Mortazavi H. Clinical and pathological evaluation of patients with early and late recurrence of colorectal cancer. Asia Pac J Clin Oncol 2010;6:35-41. 